\title{
Circulating nucleic acids: An analysis of their occurrence in malignancies (Review)
}

\author{
SHANKAR SURAJ ${ }^{1}$, CHIRAG DHAR $^{2}$ and SWETA SRIVASTAVA ${ }^{1}$ \\ ${ }^{1}$ Department of Transfusion Medicine and Immunohematology, St. John's Medical College and Hospital; \\ ${ }^{2}$ St. John's Research Institute, St. John's National Academy of Health Sciences, Bangalore, Karnataka 560034, India
}

Received May 30, 2016; Accepted September 15, 2016

DOI: $10.3892 /$ br.2016.812

\begin{abstract}
Through a regulated or fortuitous phenomenon, small portions of cell nucleic acids are thrown into circulation. Since the discovery of these circulating nucleic acids (CNAs) in 1948, numerous studies have been published to elucidate their clinical implications in multifarious diseases. Scientists have now discovered disease-specific genetic aberrations, such as mutations, microsatellite alterations, epigenetic modulations (including aberrant methylation), as well as viral DNA/RNA from nucleic acids in plasma and serum. CNAs have become increasingly popular due to their potential for use as a liquid biopsy, which is a tool for non-invasive diagnosis and monitoring of diseases, such as cancer, stroke, trauma, myocardial infarction, autoimmune disorders, and pregnancy-associated complications. While the diagnostic potential of CNAs has been investigated extensively, there is a paucity of understanding of their pathophysiological functions. Are these CNAs part of the cell's regular framework of functioning? Or do they act as molecular players in disease initiation and progression? The aim of this review is to investigate the origins and functions of the circulating cell-free nucleic acids in the plasma and serum of patients with various malignancies, and propose areas of study, which may elucidate the novel underlying mechanisms that are functioning during cancer initiation/progression.
\end{abstract}

Correspondence to: Dr Sweta Srivastava, Department of Transfusion Medicine and Immunohematology, St. John's Medical College and Hospital, St. John's National Academy of Health Sciences, Sarjapur Road, Bangalore, Karnataka 560034, India E-mail: sweta.s@stjohns.in

Abbreviations: CNAs, circulating nucleic acids; cfDNA, cell free deoxyribonucleic acid; ctDNA, circulating tumour deoxyribonucleic acid; RNA, ribonucleic acid; DNA, deoxyribonucleic acid; HPV, human papilloma virus; EBV, ebstein barr virus; HBV, hepatitis B virus; miRNA, micro ribonucleic acids; mtDNA, mitochondrial deoxyribonucleic acid

Key words: circulating nucleic acids, circulating tumour deoxyribonucleic acid, liquid biopsy, cancer, metastasis, immune escape

\section{Contents}

1. Introduction

2. Origins and mechanisms of CNA release

3. Applications of CNAs

4. Quantification of CNAs

5. Cancer specific biomarkers

6. Physiology/pathophysiology of CNAs

7. Conclusion

\section{Introduction}

In March 2016, a landmark publication by Margolin et al (1) showed the presence of a highly conserved hypermethylation signature in circulating nucleic acids (CNAs) present in blood across a multitude of cancer types. Such a pan-cancer biomarker, if validated, may present as a strong diagnostic tool in the fight against cancer. However, our knowledge of CNAs and their resurgence as important factors in cancer pathogenesis will determine their development as an effective diagnostic tool.

The term CNAs refers to segments of genomic, mitochondrial or viral DNA, RNA and microRNA (miRNA) found in the bloodstream (2). The history of CNAs dates back to the 1940s, when Metais and Mandel reported the presence of free nucleic acids in plasma (3). Over the past decade, the unequivocal proof that certain CNAs are of tumor origin (4) has initiated a surge of studies. This has led to a wealth of information indicating the diagnostic potential of these CNAs, particularly in cancer screening and monitoring of the efficacy of anticancer therapeutic strategies (5).

There are various mechanisms by which these nucleic acids are proposed to be released into circulation. These include passive mechanisms, including apoptosis and necrosis (6) or active mechanisms, such as spontaneous release of nucleic acids from cells (7). While numerous studies have been conducted to determine the mechanism by which circulating DNA/RNA fragments are released into the blood, the sources of these CNAs remain elusive. Certain theories include circulating tumor cells (8), stem cells (9), blood cells/lymphocytes (10), and viruses [ebstein barr virus (EBV) and human papilloma virus (HPV)] $(11,12)$ as potential origins of these cell-free nucleic acids in circulation.

Information regarding the source and mechanisms of the release of these CNAs may present an insight into their 
possible roles or functions in the body. A clear understanding of all the potential functions and influences of CNAs would add marked prognostic value to the assessment of CNAs, in addition to an already established role in disease diagnosis and monitoring.

\section{Origins and mechanisms of CNA release}

While the existence of cell-free nucleic acids in the bloodstream has been shown by a number of studies, there is a lack of clarity regarding their source(s) (13). In 1998, it was shown that plasma or serum DNA often presents a ladder pattern when subjected to electrophoresis (7), which is similar to that produced by degraded DNA fragments from apoptotic cells (14-17). Since then, numerous reports on circulating DNA have indicated apoptosis or necrosis as the main phenomenon responsible for cell-free CNAs $(6,7,18,19)$. While certain nucleic acids in plasma/serum maybe released through apoptosis or necrosis, these are certainly not the only mechanisms responsible for their presence in circulation. This is evident from studies in cancer patients, showing decreased quantities of circulating DNA following chemotherapy/radiotherapy-induced apoptosis (20).

In addition to apoptosis and necrosis, the phenomenon of active release of DNA from cells is expected to be a mechanism of CNA's release into plasma (10). In 1975 , Anker et al (21) showed that living cells are capable of spontaneously releasing newly synthesized DNA in a preferential manner. The study demonstrated that non-dividing cells, such as lymphocytes, frog auricles and cultured cell lines, including HL-60, spontaneously discharged a nucleoprotein complex within a homeostatic system in which newly synthesized DNA was released preferentially (21). Further evidence for preferential release of DNA by viable cells was demonstrated by Stroun et al (22). In their study, the proportion of Alu repeat sequences to $\beta$-globin gene in the serum and lymphocytes of 27 cancer patients and 22 healthy controls was compared. The proportion of Alu gene to $\beta$-globin gene was observed to be significantly higher in serum DNA than in the DNA from lymphocytes. This was observed in the control subjects $(\mathrm{P}=0.003)$ and cancer patients $(\mathrm{P}<0.001)(22)$. This leads to the hypothesis that active DNA release may be significantly involved in marking the presence of extracellular nucleic acids. Another study indicated that active release may also occur during division of normal and malignant cells in the body (10).

Thus far, the origin of CNAs has been attributed to the known mechanism of dying cells releasing their cell contents and to the unknown mechanism of living cells releasing newly synthesized DNA in a preferential manner. Through mechanisms, which remain unclear, circulating tumor cells (CTCs) have been hypothesized to also contribute to the pool of CNAs in the bloodstream (23-25). This theory is supported by studies involving lung (26), prostate (27) and breast carcinomas (28), where clear correlations between CTCs and tumor-derived CNAs (methylated DNA, miRNA and microsatellite alterations) are demonstrated. However, even in the case of advanced disease, the mass of CTCs does not account for the quantity of tumor-derived CNAs present $(5,13)$. This indicates that CTCs may contribute to only a small percentage of the total CNAs observed in plasma/serum.
Another possible origin of CNAs in plasma/serum is from viruses, such as EBV, HPV and hepatitis B virus. The presence of these circulating viral DNAs is observed in cases of healthy individuals, and in cases of malignancies associated with viral infection, such as nasopharyngeal carcinoma (11), cervical carcinoma (12) and hepatocellular carcinoma (29).

Although a variety of unrelated conditions mark the presence of these CNAs in the bloodstream, there may be a correlation between their source and functions. Evidences suggesting the role of CNAs in regular functioning $(30,31)$ and the pathophysiology of cancers (13) leads to the evaluation of whether the origins and mechanisms of CNA release differ between normal and tumor-specific microenvironments. If this is the case, it strengthens the hypothesis that CNAs are significantly involved in modulating the microenvironment to either maintain normal cellular functioning or drive the cells towards tumorigenesis/metastasis. However, if no such difference in release mechanisms actually exists, the observation of nucleic acids circulating in the bloodstream will remain primarily significant for diagnostic screening purposes.

\section{Applications of CNAs}

In recent years, there has been a considerable focus on the requirement for a non-invasive blood-based biomarker for cancer treatment. CNAs have become prominent due to their potential use as surrogate indicators for disease monitoring by early identification of disease progression and recurrence (32-35). In addition, CNAs have been identified as useful for monitoring tumor burden (36), are associated with minimal residual disease (37), tumor heterogeneity (38), detecting resistance to therapy (39), and also proven to be effective in the early diagnosis of different types of cancer (35), as schematically represented in Fig. 1.

\section{Quantification of CNAs}

It has now been established that higher concentrations of free CNAs are found in the blood of patients with malignant diseases when compared with healthy subjects $(10,40,41)$. Furthermore, a correlation has been established between the concentrations of specific sequences of nucleic acids in circulation and the disease stage $(2,42)$. Numerous studies have confirmed the use of measuring the quantity of CNAs in plasma for monitoring colon (43), breast (44), lung (45), stomach (46) and esophagus (47) cancer. While this method of quantifying CNAs has shown promise in certain studies for disease screening and monitoring, no direct association between these features has been demonstrated. Although, theoretically, the levels of cell free DNA (cfDNA) in plasma are affected by various clinicopathological features, such as tumor size, tumor stage or metastasis, there is currently a lack of studies that confirm this in human cohorts. These may be due to overlapping concentrations of cfDNA, found in healthy individuals under physiological stress (for example during physical exercise) (48) or in patients affected by other pathological processes, such as inflammation, trauma or sepsis (49).

It has been reported that plasma levels of CNAs decreased in cancer patients following surgical treatments and/or chemoradiotherapy $(20,43,44,47)$, which was probably due to the 


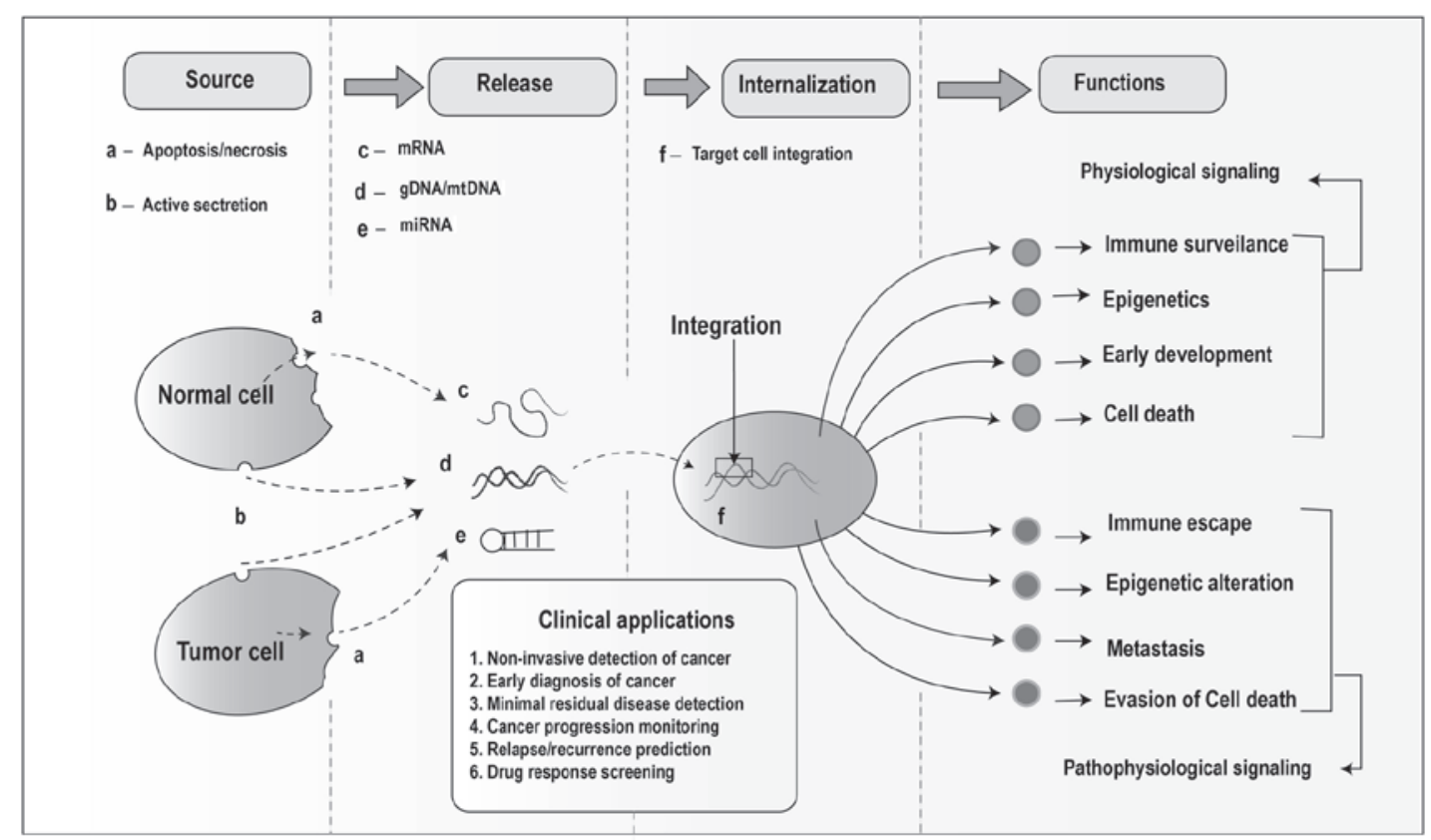

Figure 1. Circulating nucleic acids. Schematic representation of the cell origins and functions. mRNA, messenger RNA; gDNA, genomic DNA; mtDNA, mitochondrial DNA; miRNA, microRNA.

inhibitory effect of treatment on the proliferation of cancer cells. These studies also indicated that patients who maintained high levels of cfDNA in the plasma either did not respond to the treatment or were at high risk of a possible relapse. This indicates that, with further investigations and establishment of a statistical standard, the quantification of cfDNA in plasma will be of particular clinical value in disease monitoring.

\section{Cancer specific biomarkers}

Characteristics of tumor DNA have been found in genetic material extracted from the plasma of cancer patients (50). These include decreased strand stability (Integrity Index) (51-53), microsatellite alterations (indicating loss of heterozygosity or microsatellite instability) $(54,55)$, epigenetic alterations (gene hypermethylations) $(56,57)$ and presence of specific mutations in oncogenes/tumor suppressor genes [including APC, WNT signaling pathway regulator, KRAS proto-oncogene (KRAS), GTPase, tumor protein p53, phosphatidylinositol-4,5-bisphosphate 3-kinase catalytic subunit $\alpha$ and B-Raf proto-oncogene, serine/threonine kinase $(B R A F)](2,28,41)$. A recent study on circulating cell free-DNA in colorectal cancer (CRC) showed $100 \%$ specificity and sensitivity for the BRAF V600E mutation and $98 \%$ specificity and 92 sensitivity for detection of KRAS point mutations (58). The same study indicated that overall, $100 \%$ of patients with CRC expressed detectable levels of tumor-specific cfDNA.

As mentioned above, one study showed that detection of hypermethylation of the $\mathrm{CpG}$ island of Zinc Finger Protein 154 in circulating tumour DNA is a strong candidate for a future pan-cancer biomarker (1). The study demonstrated that this hypermethylation signature was consistent in colon, lung, breast, stomach and endometrial tumors. The detection of these alterations represents one of the most promising advances in improved diagnosis and monitoring of various cancer types. Non-invasive tests such as these, may potentially replace tumor-section analysis, thereby expanding the scope of personalized medicine for patients with cancer.

In addition to cfDNA, specific mRNAs have been subsequently reported to be present in the plasma (59) of patients with various types of cancer, including colon $(60,61)$, breast $(62)$, prostate (63), melanoma (64), lung (65) and thyroid (66). As free RNA molecules are likely to be degraded by RNase outside the cell, it is likely to be packaged, either through lipid vesicles (59), or RNA-binding proteins (67), for protection. Furthermore, it has been demonstrated that miRNA are significantly involved in control of cell proliferation, cell differentiation and apoptosis (68); thus, their dysregulation is known to contribute towards tumor development. Levels of circulating miRNA, as well as various mRNAs, have been shown to be associated with the different stages and types of cancer $(69,70)$.

Although the investigation of genetic and epigenetic alterations of genomic DNA is predominantly adopted in cancer research, the identification of cancer-specific alterations in mitochondrial DNA (mtDNA) has helped to expand the search for clinical tools (71). The alterations in mtDNA, which are point mutations, deletions, insertions and quantitative changes, have been detected in a wide range of tumor types, such as breast, colon, liver, head and neck, and lung (72,73).

In addition to the circulating endogenous DNA, RNA, miRNA and mtDNAs, exogenous viral DNA in plasma has been demonstrated as a powerful diagnostic tool and its quantification may present marked prognostic value. A study on cervical cancer indicated $81 \%$ sensitivity (13/16) in detecting circulating (c-)HPVDNA in patients who have progressed beyond stage 1B (74). The same study showed correlations between $\mathrm{c}-\mathrm{HPV}$, and response to chemotherapy and disease progression. Notably, this study demonstrated increasing quantities of c-HPV DNA, which was observed 6 months prior 
to a patient's relapse. This illustrates the potential of circulating viral DNA in predicting disease recurrences.

A recent study by Bettegowda et al (35) indicated that in patients with localized tumors, ctDNA was detectable in 73,57, 48 and $50 \%$ of patients with colorectal cancer, gastroesophageal cancer, pancreatic cancer, and breast adenocarcinoma, respectively. It was also found that ctDNA was detectable in $>75 \%$ of patients with advanced malignancies in pancreatic, ovarian, colorectal, bladder, gastroesophageal, breast, melanoma, hepatocellular, and head and neck cancers. The same study, however, indicated that while the sensitivity of detection of disease-specific CNAs was considerably high in certain malignancies, it was detected in $<50 \%$ of primary brain, renal, prostate, or thyroid cancers (35). This selective sensitivity in detection of circulating tumor nucleic acids presents an insight into the role of CNAs in establishing a malignant physiology.

\section{Physiology/pathophysiology of CNAs}

While the role of CNAs in diagnostics has been investigated extensively, the reason for their presence remains uncertain. The fact that normal blood cells (lymphocytes) and many other types of living cells release nucleic acids into circulation $(21,75)$ indicates the possibility of these CNAs being involved in the normal functioning of cells. A theory of intercommunication between cells via release of nucleic acids acting as signaling molecules was proposed by Gardiner et al (31). Recent evidence from different fields indicate active trafficking of nucleic acids between cells through carrier mechanisms on the cell membrane (30). Nucleic acid trafficking may be involved in intercellular signaling during development, epigenetic remodelling, tissue regeneration and fine-tuning of the adaptive immune system. In addition, it may be involved in cancer development and immune surveillance (30).

The role of the immune system in cancer has become increasingly evident over the past decade. The immune system is widely known to interact closely with tumors over the entire process of disease development and progression to metastasis (76), and is now classified as a hallmark of cancer (77). The mechanisms by which different types of cancer evade the immune response has been attributed to higher suppressive activity of $\mathrm{T}$ regulatory cells (78), defective antigen presentation (79), immune suppressive mediators (80), immunoediting (81) and selective deletion of tumor-specific cytotoxic T-lymphocytes (82). It is possible that CNAs act as modulators of the immune system. In studies regarding fetal-derived CNAs in the bloodstream (83), it has been shown that foreign DNA is recognized by Toll-like receptor (TLR) 9 , and RNA is recognized by TLR3 on immune cells, which activate inflammatory processes $(84,85)$. This CNA-TLR signaling has been shown to be significant for the reactivation of immunity in pregnancy during labor (83). Similar interaction between CNAs and immune receptors is hypothesized to contribute towards cancer (20).

Immune responses are tightly regulated; just as TLR stimulation will activate responses it will also suppress them so as to prevent autoimmunity (86), thus indicating the possible role of CNAs in cancer and normal environments, respectively. Therefore, an improved understanding of the role of CNAs in modulating immune responses may provide insights for the development of novel therapeutic strategies, which may facilitate with overcoming the problem of immune resistance and prevent/hinder cancer progression.

In addition to the role of circulating miRNAs in gene silencing, recent studies have shown their contribution in promoting gene expression via epigenetic modulation. Place et al (87) have shown that miR-373 induced expression of E-cadherin and cold-shock domain-containing protein C2 genes with complementary sequences in their promoter regions. Furthermore, one study by Margolin et al (1) demonstrated that there exists differentially methylated DNA/miRNA in circulation. It may be possible that the release of CNAs from the dying human cancer cells is involved in modulating epigenetic mechanisms.

As it is known that cell free nucleic acids may affect the ability of a cell to evade cell death, whether cell free nucleic acids aid in the process of metastasis remains to be elucidated. A study conducted in mice showed that these CNAs, when injected intravenously, integrate into normal cells of vital organs and greatly alter the normal apoptotic pathways (88). This indicates that stretches of nucleic acids may change the expression levels of certain genes in otherwise healthy cells, thereby promoting invasion and metastasis (20). This may lead to mutations and subsequent malignant transformation in these cells, a theory termed as genometastasis $(9,88,89)$. The mechanism of cancer dissemination in the context of CNAs is not fully understood. If the role of CNAs in metastasis is validated, monitoring their levels may lead to a predictive test for metastasis and micrometastasis. Understanding the role of CNAs in metastasis may elucidate potential 'druggable' signaling pathways, which would lead to a specific treatment strategy for preventing metastasis (Fig. 1).

\section{Conclusion}

Thus far, the utility of CNAs has been evaluated in various diagnostic assays. Simple quantification of CNAs in the blood has been identified as a useful tool in determining patient prognoses. Differential methylation patterns in specific genes have the potential to turn into pan-cancer biomarkers and may serve as an effective screening tool. CNAs, right from their origin, appear to exert orchestrated activity in the pathophysiology of cancer. Conclusive proof of the influence of CNAs in immune escape mechanisms, epigenetic modulations or even as a mediator of metastasis cannot be ascertained from existing studies.

There is an ambiguity in the current understanding on CNAs regarding their possible roles in establishing a disease-specific microenvironment or their role in maintaining the regular framework of functioning. As a result of evaluating the current literature on possible functions of CNAs, we hypothesize that CNAs have an established system for modulating the microenvironment for regular cell functioning and signaling that, when altered, may lead to a particular disease pathophysiology.

Further research is required to fully understand the role of CNAs in the initiation and progression of different types of cancer. Research in this direction, however, poses its own set of challenges. Mutant CNAs of tumour origin are present in miniscule quantities as compared to the wild-type copies, particularly in early stage tumours, making detection 
a challenge. This is being addressed by novel technological advancements with high sensitivity, such as droplet digital polymerase chain reaction, Beads Emulsions Amplification and Magnetics (BEAMING) and cancer personalized profiling by deep sequencing. However, the high cost associated with these technologies hinders their utility in affordable and continued patient care. This presents a requirement for the development of low-cost alternatives, which will facilitate cancer diagnostics and screening.

\section{Acknowledgements}

The authors would like to thank Dr Cecil Ross and Professor Sudhir Krishna for their scientific discussions and inputs, and Ms. Annapurna Pranatharthi, Ms. Mugdha Sharma and Ms. Pavana Thomas for their critical comments.

\section{References}

1. Margolin G, Petrykowska HM, Jameel N, Bell DW, Young AC and Elnitski L: Robust Detection of DNA Hypermethylation of ZNF154 as a Pan-Cancer Locus with in Silico Modeling for Blood-Based Diagnostic Development. J Mol Diagn 18: 283-298, 2016.

2. González-Masiá JA, García-Olmo D and García-Olmo DC: Circulating nucleic acids in plasma and serum (CNAPS): Applications in oncology. Onco Targets Ther 6: 819-832, 2013.

3. Metais P and Mandel P: Les acides necleiques du plasma sanguin chez l'Homme. C R Acad Sci Paris 142: 241-243, 1948.

4. Fleischhacker $M$ and Schmidt B: Circulating nucleic acids (CNAs) and cancer - a survey. Biochim Biophys Acta 1775: 181-232, 2007.

5. Crowley E, Di Nicolantonio F, Loupakis F and Alberto Bardelli A: Liquid biopsy: monitoring cancer-genetics in the blood. Nature Reviews Clinical Oncology 10: 472-484, 2013.

6. Schwarzenbach H, Hoon DS and Pantel K: Cell-free nucleic acids as biomarkers in cancer patients. Nat Rev Cancer 11: 426-437, 2011.

7. Stroun M, Lyautey J, Lederrey C, Olson-Sand A and Anker P: About the possible origin and mechanism of circulating DNA apoptosis and active DNA release. Clin Chim Acta 313: 139-142, 2001.

8. Stroun M, Anker P, Maurice P, Lyautey J, Lederrey C and Beljanski M: Neoplastic characteristics of the DNA found in the plasma of cancer patients. Oncology 46: 318-322, 1989.

9. García-Olmo DC, Ruiz-Piqueras R and García-Olmo D: Circulating nucleic acids in plasma and serum (CNAPS) and its relation to stem cells and cancer metastasis: State of the issue. Histol Histopathol 19: 575-583, 2004.

10. van der Vaart $M$ and Pretorius PJ: Circulating DNA. Its origin and fluctuation. Ann N Y Acad Sci 1137: 18-26, 2008.

11. Lo YM, Chan LY, Lo KW, Leung SF, Zhang J, Chan AT, Lee JC, Hjelm NM, Johnson PJ and Huang DP: Quantitative analysis of cell-free Epstein-Barr virus DNA in plasma of patients with nasopharyngeal carcinoma. Cancer Res 59: 1188-1191, 1999.

12. Yang HJ, Liu VW, Tsang PC, Yip AM, Tam KF, Wong LC, Ng TY and Ngan HY: Quantification of human papillomavirus DNA in the plasma of patients with cervical cancer. Int J Gynecol Cancer 14: 903-910, 2004.

13. Anker P, Mulcahy H, Chen XQ and Stroun M: Detection of circulating tumour DNA in the blood (plasma/serum) of cancer patients. Cancer Metastasis Rev 18: 65-73, 1999.

14. Giacona MB, Ruben GC, Iczkowski KA, Roos TB, Porter DM and Sorenson GD: Cell-free DNA in human blood plasma: Length measurements in patients with pancreatic cancer and healthy controls. Pancreas 17: 89-97, 1998.

15. Nagata S, Nagase H, Kawane K, Mukae N and Fukuyama H: Degradation of chromosomal DNA during apoptosis. Cell Death Differ 10: 108-116, 2003.

16. Holdenrieder S and Stieber P: Apoptotic markers in cancer. Clin Biochem 37: 605-617, 2004.

17. Nagata S: DNA degradation in development and programmed cell death. Annu Rev Immunol 23: 853-875, 2005.
18. Atamaniuk J, Ruzicka K, Stuhlmeier KM, Karimi A, Eigner M and Mueller MM: Cell-free plasma DNA: A marker for apoptosis during hemodialysis. Clin Chem 52: 523-526, 2006.

19. Fournié GJ, Courtin JP, Laval F, Chalé JJ, Pourrat JP, Pujazon MC, Lauque D and Carles P: Plasma DNA as a marker of cancerous cell death. Investigations in patients suffering from lung cancer and in nude mice bearing human tumours. Cancer Lett 91: 221-227, 1995.

20. Chen Z, Fadiel A, Naftolin F, Eichenbaum KD and Xia Y: Circulation DNA: Biological implications for cancer metastasis and immunology. Med Hypotheses 65: 956-961, 2005.

21. Anker P, Stroun M and Maurice PA: Spontaneous release of DNA by human blood lymphocytes as shown in an in vitro system. Cancer Res 35: 2375-2382, 1975.

22. Stroun M, Lyautey J, Lederrey C, Mulcahy HE and Anker P: Alu repeat sequences are present in increased proportions compared to a unique gene in plasma/serum DNA: Evidence for a preferential release from viable cells? Ann N Y Acad Sci 945: 258-264, 2001.

23. Alix-Panabières $\mathrm{C}$, Schwarzenbach $\mathrm{H}$ and Pantel K: Circulating tumor cells and circulating tumor DNA. Annu Rev Med 63: 199-215, 2012.

24. Bidard FC, Weigelt B and Reis-Filho JS: Going with the flow: From circulating tumor cells to DNA. Sci Transl Med 5: 207ps14, 2013.

25. Ignatiadis M and Dawson SJ: Circulating tumor cells and circulating tumor DNA for precision medicine: Dream or reality? Ann Oncol 25: 2304-2313, 2014.

26. Roth C, Kasimir-Bauer S, Pantel K and Schwarzenbach H: Screening for circulating nucleic acids and caspase activity in the peripheral blood as potential diagnostic tools in lung cancer. Mol Oncol 5: 281-291, 2011.

27. Altimari A, Grigioni AD, Benedettini E, Gabusi E, Schiavina R, Martinelli A, Morselli-Labate AM, Martorana G, Grigioni WF and Fiorentino M: Diagnostic role of circulating free plasma DNA detection in patients with localized. Am J Clin Pathol 129: 756-762, 2008.

28. Schwarzenbach H: Circulating nucleic acids as biomarkers in breast cancer. Breast Cancer Res 15: 211, 2013.

29. Ono A, Fujimoto A, Yamamoto Y, Akamatsu S, Hiraga N, Imamura M, Kawaoka T, Tsuge M, Abe H, Hayes CN, et al: Circulating Tumor DNA Analysis for Liver Cancers and Its Usefulness as a Liquid Biopsy. Cellular and Molecular Gastroenterology and Hepatology 1: 516-534, 2015.

30. Ho MW: Intercommunication via circulating nucleic acids. Science in Society 42, 46-48, 2009.

31. GardinerC,HarrisonP,Belting M,Böing A,CampelloE,Carter BS, Collier ME, Coumans F, Ettelaie C, van Es N, et al: Extracellular vesicles, tissue factor, cancer and thrombosis - discussion themes of the ISEV 2014 Educational Day. J Extracell Vesicles 4: 26901, 2015.

32. Garcia-Murillas I, Schiavon G, Weigelt B, Ng C, Hrebien S, Cutts RJ, Cheang M, Osin P, Nerurkar A, Kozarewa I, et al: Mutation tracking in circulating tumor DNA predicts relapse in early breast cancer. Sci Transl Med 7: 302ra133, 2015.

33. Umetani N, Giuliano AE, Hiramatsu SH, Amersi F, Nakagawa T, Martino S and Hoon DS: Prediction of breast tumor progression by integrity of free circulating DNA in serum. J Clin Oncol 24: 4270-4276, 2006.

34. Hamakawa T, Kukita Y, Kurokawa Y, Miyazaki Y, Takahashi T, Yamasaki M, Miyata H, Nakajima K, Taniguchi K and Takiguchi S: Monitoring gastric cancer progression with circulating tumour DNA. Br J Cancer 112: 352-356, 2015.

35. Bettegowda C, Sausen M, Leary RJ, Kinde I, Wang Y, Agrawal N, Bartlett BR, Wang H, Luber B, Alani RM, et al: Detection of circulating tumor DNA in early- and late-stage human malignancies. Sci Transl Med 6: 224ra24, 2014.

36. Figg WD II and Reid J: Monitor tumor burden with circulating tumor DNA. Cancer Biol Ther 14: 697-698, 2013.

37. Roschewski M, Dunleavy K, Pittaluga S, Kong K, Shovlin M, Jaffe ES, Staudt LM, Lai C, Chen CC, Zheng J, et al: Monitoring of Circulating Tumor DNA As Minimal Residual Disease in Diffuse Large B-Cell Lymphoma. Blood 124: 139, 2014.

38. De Mattos-Arruda L, Weigelt B, Cortes J, Won HH, Ng CKY, Nuciforo P, Bidard FC, Aura C, Saura C, Peg V, et al: Capturing intra-tumor genetic heterogeneity by de novo mutation profiling of circulating cell-free tumor DNA: A proof-of-principle. Ann Oncol 25: 1729-1735, 2014.

39. Siravegna G and Bardelli A: Genotyping cell-free tumor DNA in the blood to detect residual disease and drug resistance. Genome Biol 15: 449, 2014. 
40. Yoon KA, Park S, Lee SH, Kim JH and Lee JS: Comparison of circulating plasma DNA levels between lung cancer patients and healthy controls. J Mol Diagn 11: 182-185, 2009.

41. Diehl F, Schmidt K, Choti MA, Romans K, Goodman S, Li M, Thornton K, Agrawal N, Sokoll L, Szabo SA, et al: Circulating mutant DNA to assess tumor dynamics. Nat Med 14: 985-990, 2008.

42. García-Olmo DC, Samos J, Picazo MG, Asensio AI, Toboso I and García-Olmo D: Release of cell-free DNA into the bloodstream leads to high levels of non-tumor plasma DNA during tumor progression in rats. Cancer Lett 272: 133-140, 2008.

43. Frattini M, Gallino G, Signoroni S, Balestra D, Battaglia L, Sozzi G, Leo E, Pilotti S and Pierotti MA: Quantitative analysis of plasma DNA in colorectal cancer patients: a novel prognostic tool. Ann N Y Acad Sci 1075: 185-190, 2006.

44. Catarino R, Ferreira MM, Rodrigues H, Coelho A, Nogal A, Sousa A and Medeiros R: Quantification of free circulating tumor DNA as a diagnostic marker for breast cancer. DNA Cell Biol 27: 415-421, 2008.

45. Sozzi G, Conte D, Leon M, Ciricione R, Roz L, Ratcliffe C, Roz E, Cirenei N, Bellomi M, Pelosi G, et al: Quantification of free circulating DNA as a diagnostic marker in lung cancer. J Clin Oncol 21: 3902-3908, 2003

46. Sai S, Ichikawa D, Tomita H, Ikoma D, Tani N, Ikoma H, Kikuchi S, Fujiwara H, Ueda Y and Otsuji E: Quantification of plasma cell-free DNA in patients with gastric cancer. Anticancer Res 27 (4C): 2747-2751, 2007.

47. Tomita H, Ichikawa D, Ikoma D, Sai S, Tani N, Ikoma H, Fujiwara H, Kikuchi S, Okamoto K, Ochiai T, et al: Quantification of circulating plasma DNA fragments as tumor markers in patients with esophageal cancer. Anticancer Res 27 (4C): 2737-2741, 2007.

48. Atamaniuk J, Vidotto C, Tschan H, Bachl N, Stuhlmeier KM and Müller MM: Increased concentrations of cell-free plasma DNA after exhaustive exercise. Clin Chem 50: 1668-1670, 2004.

49. Lo YM, Rainer TH, Chan LY, Hjelm NM and Cocks RA: Plasma DNA as a prognostic marker in trauma patients. Clin Chem 46: 319-323, 2000

50. Jacobs EL and Haskell CM: Clinical use of tumor markers in oncology. Curr Probl Cancer 15: 299-360, 1991.

51. Wang BG, Huang HY, Chen YC, Bristow RE, Kassauei K, Cheng CC, Roden R, Sokoll LJ, Chan DW and Shih IeM: Increased plasma DNA integrity in cancer patients. Cancer Res 63: 3966-3968, 2003

52. Umetani N, Kim J, Hiramatsu S, Reber HA, Hines OJ, Bilchik AJ and Hoon DS: Increased integrity of free circulating DNA in sera of patients with colorectal or periampullary cancer: Direct quantitative PCR for ALU repeats. Clin Chem 52: 1062-1069, 2006.

53. Umetani N, Giuliano AE, Hiramatsu SH, Amersi F, Nakagawa T, Martino S and Hoon DS: Prediction of breast tumor progression by integrity of free circulating DNA in serum. J Clin Oncol 24 4270-4276, 2006.

54. Schwarzenbach H, Müller V, Stahmann N and Pantel K: Detection and characterization of circulating microsatellite-DNA in blood of patients with breast cancer. Ann N Y Acad Sci 1022: 25-32, 2004

55. Sunami E, Shinozaki M, Higano CS, Wollman R, Dorff TB, Tucker SJ, Martinez SR, Mizuno R, Singer FR and Hoon DS: Multimarker circulating DNA assay for assessing blood of prostate cancer patients. Clin Chem 55: 559-567, 2009.

56. Esteller M, Sanchez-Cespedes M, Rosell R, Sidransky D, Baylin SB and Herman JG: Detection of aberrant promoter hypermethylation of tumor suppressor genes in serum DNA from non-small cell lung cancer patients. Cancer Res 59: 67-70, 1999.

57. Wong IH, Lo YM, Zhang J, Liew CT, Ng MH, Wong N, Lai PB, Lau WY, Hjelm NM and Johnson PJ: Detection of aberrant p16 methylation in the plasma and serum of liver cancer patients. Cancer Res 59: 71-73, 1999

58. Thierry AR, Mouliere F, El Messaoudi S, Mollevi C, Lopez-Crapez E, Rolet F, Gillet B, Gongora C, Dechelotte P, Robert B: Clinical validation of the detection of KRAS and BRAF. Nat Med 20: 430-435, 2014.

59. Etheridge A, Gomes CP, Pereira RW, Galas D and Wang K: The complexity, function and applications of RNA in circulation. Front Genet 4: 115, 2013

60. Dasí F, Lledó S, García-Granero E, Ripoll R, Marugán M, Tormo M, García-Conde J and Aliño SF: Real-time quantification in plasma of human telomerase reverse transcriptase (hTERT) mRNA: A simple blood test to monitor disease in cancer patients. Lab Invest 81: 767-769, 2001.

61. Lledó SM, Garcia-Granero E, Dasí F, Ripoli R, García SA Cervantes A and Aliño SF: Real time quantification in plasma of human telomerase reverse transcriptase (hTERT) mRNA in patients with colorectal cancer. Colorectal Dis 6: 236-242, 2004
62. Silva JM, Dominguez G, Silva J, Garcia JM, Sanchez A, Rodriguez O, Provencio M, España P and Bonilla F: Detection of epithelial messenger RNA in the plasma of breast cancer patients is associated with poor prognosis tumor characteristics. Clin Cancer Res 7: 2821-2825, 2001.

63. Dasí F, Martínez-Rodes P, March JA, Santamaría J, Martínez-Javaloyas JM, Gil M and Aliño SF: Real-time quantification of human telomerase reverse transcriptase mRNA in the plasma of patients with prostate cancer. Ann N Y Acad Sci 1075: 204-210, 2006.

64. Kopreski MS, Benko FA, Kwak LW and Gocke CD: Detection of tumor messenger RNA in the serum of patients with malignant melanoma. Clin Cancer Res 5: 1961-1965, 1999.

65. Kopreski MS, Benko FA and Gocke CD: Circulating RNA as a tumor marker: detection of 5T4 mRNA in breast and lung cancer patient serum. Ann N Y Acad Sci 945: 172-178, 2001.

66. Chinnappa P, Taguba L, Arciaga R, Faiman C, Siperstein A, Mehta AE, Reddy SK, Nasr C and Gupta MK: Detection of thyrotropin-receptor messenger ribonucleic acid (mRNA) and thyroglobulin mRNA transcripts in peripheral blood of patients with thyroid disease: Sensitive and specific markers for thyroid cancer. J Clin Endocrinol Metab 89: 3705-3709, 2004.

67. Turchinovich A, Weiz L and Burwinkel B: Isolation of circulating microRNA associated with RNA-binding protein. Methods Mol Biol 1024: 97-107, 2013.

68. Iorio MV and Croce CM: MicroRNAs in cancer: Small molecules with a huge impact. J Clin Oncol 27: 5848-5856, 2009.

69. Mitchell PS, Parkin RK, Kroh EM, Fritz BR, Wyman SK, Pogosova-Agadjanyan EL, Peterson A, Noteboom J, O'Briant KC, Allen A, et al: Circulating microRNAs as stable blood-based markers for cancer detection. Proc Natl Acad Sci USA 105: 10513-10518, 2008.

70. Chen X, Ba Y, Ma L, Cai X, Yin Y, Wang K, Guo J, Zhang Y, Chen J, Guo X, et al: Characterization of microRNAs in serum: A novel class of biomarkers for diagnosis of cancer and other diseases. Cell Res 18: 997-1006, 2008.

71. Yu M: Somatic mitochondrial DNA mutations in human cancers. Adv Clin Chem 57: 99-138, 2012.

72. Chiu RW, Chan LY, Lam NY, Tsui NB, Ng EK, Rainer TH and Lo YM: Quantitative analysis of circulating mitochondrial DNA in plasma. Clin Chem 49: 719-726, 2003.

73. Copeland WC, Wachsman JT, Johnson FM and Penta JS: Mitochondrial DNA alterations in cancer. Cancer Invest 20: 557-569, 2002.

74. Campitelli M, Jeannot E, Peter M, Lappartient E, Saada S, de la Rochefordière A, Fourchotte V, Alran S, Petrow P, Cottu $\mathrm{P}$, et al: Human papillomavirus mutational insertion: Specific marker of circulating tumor DNA in cervical cancer patients. PLoS One 7: e43393, 2012.

75. van der Vaart $M$ and Pretorius PJ: The origin of circulating free DNA. Clin Chem 53: 2215, 2007.

76. Vinay DS, Ryan EP, Pawelec G, et al: Immune evasion in cancer: Mechanistic basis and therapeutic strategies. Semin Cancer Biol 35: S185-S198, 2015.

77. Hanahan D and Weinberg RA: Hallmarks of cancer: The next generation. Cell 144: 646-674, 2011.

78. Zou W: Regulatory $\mathrm{T}$ cells, tumour immunity and immunotherapy. Nat Rev Immunol 6: 295-307, 2006.

79. Johnsen AK, Templeton DJ, Sy M and Harding CV: Deficiency of transporter for antigen presentation (TAP) in tumor cells allows evasion of immune surveillance and increases tumorigenesis. J Immunol 163: 4224-4231, 1999.

80. Gabrilovich D: Mechanisms and functional significance of tumour-induced dendritic-cell defects. Nat Rev Immunol 4: 941-952, 2004

81. Dunn GP, Bruce AT, Ikeda H, Old LJ and Schreiber RD: Cancer immunoediting: From immunosurveillance to tumor escape. Nat Immunol 3: 991-998, 2002.

82. Lauritzsen GF, Hofgaard PO, Schenck K and Bogen B: Clonal deletion of thymocytes as a tumor escape mechanism. Int $\mathrm{J}$ Cancer 78: 216-222, 1998

83. Enninga EA, Nevala WK, Holtan SG and Markovic SN: Immune reactivation by cell-free fetal DNA in healthy pregnancies re-purposed to target tumors: Novel checkpoint inhibition in cancer therapeutics. Front Immunol 6: 424, 2015.

84. Krieg AM, Yi AK, Matson S, Waldschmidt TJ, Bishop GA, Teasdale R, Koretzky GA and Klinman DM: CpG motifs in bacterial DNA trigger direct B-cell activation. Nature 374: 546-549, 1995. 
85. Zhang SY, Jouanguy E, Ugolini S, Smahi A, Elain G, Romero P, Segal D, Sancho-Shimizu V, Lorenzo L, Puel A, et al: TLR3 deficiency in patients with herpes simplex encephalitis. Science 317: $1522-1527,2007$.

86. Wölfle SJ, Strebovsky J, Bartz H, Sähr A, Arnold C, Kaiser C, Dalpke AH and Heeg K: PD-L1 expression on tolerogenic APCs is controlled by STAT-3. Eur J Immunol 41: 413-424, 2011.

87. Place RF, Li LC, Pookot D, Noonan EJ and Dahiya R: MicroRNA-373 induces expression of genes with complementary promoter sequences. Proc Natl Acad Sci USA 105: 1608-1613, 2008 .
88. García-Olmo DC, Domínguez C, García-Arranz M, Anker P, Stroun M, García-Verdugo JM and García-Olmo D: Cell-free nucleic acids circulating in the plasma of colorectal cancer patients induce the oncogenic transformation of susceptible cultured cells. Cancer Res 70: 560-567, 2010.

89. Mittra I, Khare NK, Raghuram GV, Chaubal R, Khambatti F, Gupta D, Gaikwad A, Prasannan P, Singh A, Iyer A, et al: Circulating nucleic acids damage DNA of healthy cells by integrating into their genomes. J Biosci 40: 91-111, 2015. 